\title{
EL ROL DE BRASIL EN EL REGIONALISMO LATINOAMERICANO: LA APUESTA POR UNA INSERCIÓN INTERNACIONAL SOLITARIA Y UNILATERAL
}

\author{
BRAZIL'S ROLE IN LATIN AMERICA'S REGIONALISM: \\ THE COMMITMENT TO A SOLITARY AND UNILATERAL \\ INTERNATIONAL INSERTION
}

\author{
LE RÔLE DU BRÉSIL DANS LE RÉGIONALISME \\ LATINO-AMÉRICAIN: LE PARI SUR UNE INSERTION \\ INTERNATIONALE SOLITAIRE ET UNILATÉRALE
}

\author{
Javier A. VAdell \\ Pontificia Universidade Católica de \\ Minas Gerais (PUC Minas) \\ javier.vadell@pucminas.br \\ Clatisa Giaccaglia \\ Universidad Nacional de Rosario (UNR) \\ clagiaccaglia@yahoo.com.ar
}

\begin{abstract}
REsumen: A inicios del siglo xxI, Brasil se constituyó en un protagonista crucial como principal articulador del proyecto integracionista de Sudamérica. Al ya existente Mercosur se le sumó la creación de Unasur, reafirmando la construcción de políticas regionales en torno a la idea de "Sudamérica". En la actualidad, sin embargo, la retracción del liderazgo brasileño, junto con los virajes y desorientaciones ocurridos en Unasur y en Mercosur, han dañado la credibilidad de las iniciativas de la región, así como la posibilidad de identificar una voz conjunta en Sudamérica. Pese a ello, creemos que difícilmente podría hablarse de un desacoplamiento total de Brasil de la subregión o, dicho de otro modo, de un abandono efectivo de los regionalismos. El reconocimiento de las vicisitudes distintivas por las que han atravesado los Estados latinoamericanos nos lleva más bien a pensar en un entramado complejo y desordenado, en el cual el devenir político institucional de Brasil tendrá relevantes repercusiones para el futuro de la región.

Palabras clave: América Latina; Sudamérica; regionalismo; Brasil; política exterior
\end{abstract}


Aвstract: In the early 21st Century, Brazil established itself as a crucial protagonist and principal coordinator of the South American integrationist project. In addition to the existing Mercosur, Unasur was created, encompassing the entire subcontinent, and thereby reaffirming the formulation of regional policies based on the concept of "South America". Now however, the withdrawal of Brazilian leadership in South America combined with shifts and lack of direction within Unasur and Mercosur have damaged the credibility of the initiatives in the region, as well as the possibility of identifying a concerted voice in South America. Nevertheless, it is too soon to speak of a complete decoupling of Brazilian from the sub-region, that is, an effective abandonment of regionalism. Recognizing the distinctive histories of Latin American and Caribbean countries gives rise to a complex and disorganized structure in which the political and institutional course of Brazil will have significant repercussions for the future of the region.

Keywords: Latin America; South America; Brazil; foreign policy.

\section{Traducción de GonZalo Celorio Morayta}

RÉSumÉ: Au début du XXIe siècle, le Brésil s'est retrouvé acteur important, dont le rôle était de coordonner le projet d'intégration de l'Amérique du Sud. L'Union des nations sud-américaines (Unasur) se joignait au Marché commun du Sud (Mercosur), ce qui renforçait l'élaboration de politiques régionales inspirées de l'idée d'une Amérique du Sud. De nos jours, cependant, l'affaiblissement du rôle dirigeant du Brésil s'ajoute aux virages et à la désorientation de l'Unasur et du Mercosur, ce qui a diminué la crédibilité de leurs initiatives, ainsi que la possibilité d'entendre une voix unifiée de l'Amérique du Sud. Cependant, nous ne croyons pas que le Brésil se soit complètement désengagé de la région ni que les régionalismes aient été abandonnés. La constatation des difficultés auxquelles les états latino-américains ont dû faire face nous mène plutôt à évoquer un paysage compliqué et désordonné, où l'avenir politique et institutionnel du Brésil aura des effets importants sur le sort de la région entière.

Mots clefs: Amérique latine; Amérique du Sud; régionalisme; Brésil; politique étrangère.

\section{Traducción de Bernardo Mabire}

Fecha de recepción: marzo de 2019

Fecha de aceptación: enero de 2020 


\section{INTRODUCCIÓN}

\section{$\mathrm{E}$}

1 regionalismo ha constituido uno de los ejes centrales de las relaciones internacionales latinoamericanas. Los deseos integracionistas han sido históricamente contemplados por la producción académica de la región, así como también por las principales directrices de política exterior desarrolladas, a lo largo de los años, por diversos gobiernos del área.

En efecto, las raíces del regionalismo latinoamericano se confunden con el nacimiento de los Estados de la región y, pese a las vicisitudes que ha experimentado, el ideal integracionista representa la forma más ambiciosa del sentimiento regional. ${ }^{1}$ Se trata de un proceso añejo, que ha conocido sucesivos altos y bajos en función de condicionamientos tanto internos como externos. En dicho contexto, el rol del Estado brasileño como uno de los principales articuladores de los proyectos integracionistas de la región, resulta un hecho ineludible.

Durante los años cincuenta y sesenta, los gobiernos de la región, imbuidos del espíritu cepalino, defendieron una activa intervención estatal para apoyar el desarrollo industrial, las inversiones en infraestructura de transporte, comunicaciones y energía, reformas agrarias, redistribución de los ingresos y aumentos de los servicios sociales. En general, eran "coaliciones amplias y progresivas, del centro a la izquierda, de carácter urbano, modernizador, nacionalista y populista”. ${ }^{2}$ El keynesianismo, el socialismo y las teorías del desarrollo proporcionaron un respaldo teórico e ideológico para estas iniciativas. Sobre la base de estrategias nacionales de industrialización, que durante esta época se habían adoptado en la mayoría de los países de América Latina y el Caribe (ALC),

1 A. Van Klaveren, "El eterno retorno del regionalismo latinoamericano", Nueva Sociedad (275), 2018, p. 2.

${ }^{2}$ O. Sunkel, "Desarrollo e integración regional: ¿otra oportunidad para una promesa incumplida?", Revista de la CEPAL (número extraordinario), 1998, p. 234. 
se buscó crear mercados regionales mayores para aprovechar las ventajas de las economías de escala y la eficiencia del proceso de sustitución de importaciones.

En Brasil, particularmente, la integración constituyó uno de los ejes conceptuales constantes de su política exterior. ${ }^{3}$ En la década del cincuenta, el programa de gobierno de Kubitschek (1956-1961) dio prioridad al esfuerzo de industrialización, considerándolo fundamental para el desarrollo económico del país. Dicho objetivo se tradujo además en el entendimiento entre Kubitschek y el resto de los mandatarios de la región -especialmente con el presidente Frondizi de Argentina (1958-1962) - no sólo en el plano económico, sino también en el político. ${ }^{4}$ Ese clima de cooperación fue lo que posibilitó en 1960 el surgimiento de la Asociación Latinoamericana de Libre Comercio (ALALC), primer proceso de integración de la región, a partir de la propuesta del denominado ABRAmex (Argentina, Brasil y México).

Desde un punto de vista sistémico, el desenlace de las dos guerras mundiales y la Gran Depresión de 1930 habían mostrado los peligros de una dependencia excesiva de la exportación de productos primarios, por lo cual se promovió, como alternativa, el desarrollo industrial y la integración económica de la región. Dichas experiencias dieron lugar a lo que, más tarde, los especialistas denominarían "regionalismo cerrado" incluyendo iniciativas como la ya mencionada Asocia-

${ }^{3}$ A. Cervo, "Brazil's Rise on the International Scene: Brazil and the World", Revista Brasileira de Política Internacional, en Amado Cervo y Antônio Carlos Lessa (ed.), Emerging Brazil under Lula: an assessment on International Relations (2003-2010), año 53, edición especial.

${ }^{4}$ En efecto, cuando el gobierno de Kubitschek promovió la llamada Operación Panamericana, contó con un pleno respaldo de Frondizi. También en el marco de las Conferencias Panamericanas, ambos mandatarios defendieron la idea de que la mayor amenaza para sus países no estaba en las potencias extracontinentales, sino en el subdesarrollo, Gisela Pereyra Doval, La identidad nacional de Brasil en su política exterior. El caso de los gobiernos de Vargas (1930-1945), Geisel (1974-1979) y Da Silva (2003-2010), tesis doctoral, Rosario, Argentina, Universidad Nacional de Rosario, 2011, p. 170. 
ción Latinoamericana de Libre Comercio (ALALC) el Mercado Común Centroamericano (MCCA), la Comunidad del Caribe (CARICOM) y el Pacto Andino.

Resulta relevante señalar que, en ninguno de estos casos, el objetivo de construir capacidades nacionales y aprender del desarrollo industrial y tecnológico se logró plenamente. Por el contrario, frente al auge de las empresas transnacionales, los esquemas de integración regional favorecieron el enlace de subsidiarias de dichas empresas multinacionales en distintos países entre sí y con sus países sede. ${ }^{5}$

Para fines de la década del setenta y durante los años ochenta, el ideario de integración perdió interés y credibilidad, tanto por sus magros resultados como por el desenlace de acontecimientos internacionales trascendentales, como las crisis petroleras de 1973 y 1979 y el endeudamiento externo que afectó a toda la región, dando lugar a la denominada "década perdida" para toda ALC.

Pese a ello, no deben dejarse de lado ciertos esfuerzos tendientes a no abandonar los intentos integracionistas, los cuales se plasmaron en la Declaración de Iguazú firmada en 1985 por los presidentes de Brasil y Argentina, Sarney y Alfonsín. En un escenario de redemocratización regional, este acto significó el relanzamiento de las relaciones bilaterales y, sobre todo, el germen que posibilitaría la reanudación de los esquemas de integración sudamericanos concretados, años más tarde, en la creación del Mercado Común del Sur (Mercosur).

Los años noventa significaron la consolidación de regímenes democráticos en la mayoría de los países latinoamericanos. Esta situación política favoreció relaciones más estrechas, amplias y amistosas entre los gobiernos de la región, propiciando un resurgimiento del movimiento integracionista. En esta nueva etapa, se buscó hacer frente a los desafíos que generaba la globalización, a partir de políticas de liberalización económica intrarregional en el marco de los principios impartidos por el Consenso de Washington. En este sentido, a la

${ }^{5}$ Sunkel, art. cit., p. 237. 
revitalización o reestructuración de esquemas integracionistas ya existentes -como la Comunidad Andina de Naciones (CAN), se sumaron nuevas iniciativas, entre las cuales se destacó la creación del Mercosur, principal exponente del modelo de "regionalismo abierto".

En este contexto, el futuro latinoamericano pareció dividirse entre los proyectos de los dos grandes líderes latinoamericanos: México y Brasil. Mientras que el primero optó por convertirse en socio de Estados Unidos, el segundo buscó consolidar su presencia en Sudamérica marcando distancia con la potencia norteamericana. ${ }^{6}$

No caben dudas de que los regionalismos latinoamericanos experimentaron, durante la primera década de la posGuerra Fría, notables avances económicos en materia de intercambios comerciales e inversión extranjera, así como progresos políticos en el plano institucional y en materia de cooperación. Sin embargo, a fines de la década del noventa, la integración latinoamericana entró en crisis o en un periodo de "estancamiento",7 "hibernación"8 o "parálisis", 9 poniendo en evidencia ciertas vulnerabilidades vinculadas al énfasis puesto en la liberalización comercial intragrupo, en detrimento de un mayor esfuerzo para la construcción de políticas comunes.

Con respecto al Mercosur, particularmente, se hace referencia a una fase de "doble crisis", producto de la devaluación del real en Brasil en 1999 y de la crisis financiera de Argentina en 2001. Ambas situaciones provocaron una pri-

${ }^{6}$ P. Hakim, "Two Ways to Go Global”, Foreign Affairs, 81 (1), 2002.

${ }^{7} \mathrm{~J}$. A. Sanahuja, "Del 'regionalismo abierto' al 'regionalismo post-liberal'. Crisis y cambio en la integración regional en América Latina” (pp. 11-54), Alfonso Martínez, L. Peña y M. Vázquez, Anuario de la Integración Regional de América Latina y el Gran Caribe, núm. 9L, Buenos Aires, CRIES, 2008, p. 23.

${ }^{8}$ R. Miranda, Política exterior argentina. Idas y venidas entre 1999 y 2003, Rosario, Ediciones PIA, 2003, p. 26.

${ }^{9}$ R. Bouzas, "Las relaciones Unión Europea-Mercosur", Nueva Sociedad, 190, 2004, p. 64. 
macía de los intereses domésticos generando nuevos retrocesos en el esquema regional. ${ }^{10}$

El agotamiento de la estrategia de regionalismo abierto dio paso a intensos debates políticos e ideológicos en cuanto a la integración regional y a las modalidades de inserción internacional. Así, la llegada al poder de diversos gobiernos de izquierda propició el desarrollo de un modelo de integración "físico-estructural", "posliberal", "posneoliberal” o "poshegemónico".

En este contexto, Brasil -de la mano del gobierno de Lula da Silva- se constituyó en un protagonista crucial como principal articulador del proyecto integracionista. Desde esta perspectiva, al ya existente Mercosur se le sumó la creación de la Unión de Naciones Sudamericanas (Unasur) que abarcaba la totalidad del subcontinente y, por consiguiente, reafirmaba la construcción de políticas regionales en torno a la idea de "Sudamérica".

En la actualidad, luego de diez años del surgimiento de esta última iniciativa regional, una nueva fase se ha inaugurado en el marco de estos regionalismos. La dinámica latinoamericana parece hoy en día bifurcarse entre, por un lado, una reedición del regionalismo abierto - a través de la Alianza del Pacífico-y, por otro, un proceso de deconstrucción de Sudamérica como bloque geopolítico y actor regional en el sistema mundial. ${ }^{11}$ En relación con este último punto, resulta insoslayable vincular la crisis regional con la crítica coyuntura política y económica que atraviesa Brasil en tanto líder del proceso sudamericano.

Del mismo modo, la llegada de Jair Bolsonaro a la presidencia en Brasil ha profundizado la fragmentación regional en la medida en que el nuevo gobierno propicia un alejamiento del gigante sudamericano de su región de pertenencia, apostando por una inserción internacional unilateral y solitaria.

${ }^{10}$ Sanahuja, art. cit.

${ }^{11}$ D. Nolte y V. Mijares, "La crisis de Unasur y la deconstrucción de Sudamérica”, Dossier Especial: crisis de Unasur, 2018. 
Frente a los sucesos aquí detallados cabe preguntarnos: ¿qué implicaciones tienen las actuales vicisitudes por las que atraviesa la región para la supervivencia de esquemas integracionistas que posibiliten aglutinar a los gobiernos latinoamericanos en un proyecto común y propio? ¿Qué factores permiten explicar la actual fragmentación del regionalismo y la implosión de Unasur en América del Sur? ¿Cuál es el papel de Brasil en este proceso? ¿De qué manera los giros de política exterior promovidos por el gobierno de Bolsonaro atentan contra las tradiciones regionales, fragmentando tanto los esquemas de integración como el propio liderazgo regional brasileño?

Sobre la base del método histórico interpretativo, el presente trabajo tiene por objeto analizar las actuales vicisitudes que aquejan al regionalismo latinoamericano, así como el posible repliegue de Brasil como principal articulador del proceso.

En este sentido, y a modo de hipótesis de trabajo, sostenemos que la nueva fase en la que están los regionalismos latinoamericanos no puede entenderse a partir de una supuesta falta de institucionalidad-como se sostiene desde perspectivas que abogan por explicaciones en "espejo" con el proceso europeo- sino que responde en mayor medida a un proceso de redefinición propia, en función de significativas alteraciones ocurridas tanto en las coyunturas globales como nacionales que han, por tanto, incidido en la lógica regional. Asimismo, creemos que la llegada de Bolsonaro al gobierno nacional implica un quiebre en la política exterior de Brasil en relación con su esfera de pertenencia, en la medida en que ha dejado de lado el estrechamiento de relaciones regionales promovido desde la redemocratización, particularmente los lazos bilaterales con Argentina. Por el contrario, la política desarrollada por la nueva presidencia busca desacoplar a Brasil de su región, desestimando incluso probables fricciones con sus pares sudamericanos, a los efectos de propiciar una inserción internacional solitaria y unilateral acompañada de una clara alineación con Estados Unidos y un acercamiento pragmático a China. 
El artículo se enfoca, en primer lugar, en los diversos abordajes teóricos que han buscado explicar la evolución del regionalismo en ALC y, específicamente, en Sudamérica. En segundo lugar, se analiza la evolución de la reciente política externa de Brasil y los desafíos económicos y políticos para el regionalismo sudamericano en función de los cambios y vicisitudes ocurridos en el continente en los últimos tiempos. Finalmente, la última sección presenta algunas reflexiones finales.

\section{ENFOQUES SOBRE REGIONALISMO}

En el plano teórico, entre los analistas de relaciones internacionales existen algunos consensos básicos en cuanto al concepto de regionalismo. Como destacó Nolte, ${ }^{12}$ la idea de regionalismo como categoría amplia hace referencia al reconocimiento de la región como un sistema abierto y no cerrado, como sí es estudiado el sistema internacional. ${ }^{13}$ En otros términos, un sistema regional es un subsistema permeable o poroso ${ }^{14}$ influido por las dinámicas políticas y económicas, locales y nacionales, y por los constreñimientos sistémicos de la estructura económica global y de la geopolítica de las grandes potencias. Por esta razón, las regiones pueden ser pensadas como clusters geográficos, construidos políticamente por las unidades estatales e influidos por actores económicos y políticos diversos, fuerzas sociales locales, nacionales y transnacionales. Estas unidades regionales no siempre actúan como actor unitario, pero su característica es que son subsistemas abiertos, porosos a los constreñimientos globales y a las diná-

12 D. Nolte, "Potencias Regionales en la Política Regional: conceptos y enfoques de análisis”, Working Papers núm. 30, 2006.

13 D. A. Lake y P. M. Morgan, Regional orders: building security in a new world, University Park, Pa., Pennsylvania State University Press, 1997 y B. Buzan y O. Waever, Regions and powers: the structure of international security, Cambridge, Nueva York, Cambridge University Press, 2003.

${ }^{14}$ P. J. Katzenstein, A World of Regions, Londres e Ithaca, Cornell University Press, 2005. 
micas complejas de los ambientes domésticos. Una región, en este sentido, es un espacio territorial donde confluyen, de manera compleja y contradictoria, aspectos ideacionales, fuerzas sociales, instituciones políticas y redes de poder global.

En términos básicos y como punto de partida, el regionalismo presupone un "conjunto de diversos proyectos de cooperación en varias subregiones”. ${ }^{15}$ Sin embargo, es más difícil observar grados de consenso en torno a los conceptos más específicos, como la idea de integración regional o de cooperación regional. Si la integración regional es una forma avanzada de cooperación entre Estados nacionales, en un espacio geográfico específico, ¿qué tipo de cooperación sería esa? ¿Cuál es la finalidad y en qué medida podemos adoptar una teoría general de la integración?

Legler ${ }^{16}$ propone una primera clasificación entre los analistas de la integración y del regionalismo latinoamericano: las perspectivas optimistas, cuya argumentación sostiene que los cambios en el regionalismo en los 2000 provocaron transformaciones positivas en lo que respecta a la soberanía de los países, ${ }^{17}$ y las visiones más escépticas del

${ }^{15}$ A. Malamud y G. L. Gardini, "Has Regionalism Peaked? The Latin American Quagmire and its Lessons", The International Spectator: Italian Journal of International Affairs, 47 (1) 2012, pp. 116-133.

16 T. Legler, "Post-hegemonic regionalism and sovereignty in Latin America: optimists, skeptics, and an emerging research agenda", Contexto Internacional 35 (2) 2013, pp. 325-352.

${ }^{17}$ P. Riggirozzi, "Re-territorializando consensos: hacia un regionalismo post-hegemónico en América Latina”, en A. Serbin, L. Martínez y H. Ramanzini Júnior, El regionalismo "post-liberal" en América Latina y el Caribe: nuevos actores, nuevos temas, nuevos desafios. Anuario de la integración regional de América Latina y el Gran Caribe 2012, Buenos Aires, CRIES, 2012 y P. Riggirozzi, "Region, regionness and regionalism in Latin America: towards a new synthesis", New Political Economy 17, núm. 4 (2012), pp. 421-443; P. Riggirozzi y D. E. Tussie, The rise of post-hegemonic regionalism: The case of Latin America, Países Bajos, Springer, 2012; J. Preciado y A. Florido, "La Comunidad de Estados Latinoamericanos y Caribeños: integración 'postneoliberal', neoliberal ortodoxa y contrahegemónica", en Carlos Eduardo Martins y Consuelo Silva Flores (coord.), Nuevos Desafios para la Integración de América Latina, Buenos Aires, Editorial arcis clacso, 2013. 
proceso. ${ }^{18}$ No obstante, esta división remite a expectativas y anhelos que, muchas veces, han tomado la experiencia europea como modelo a seguir y que, por tanto, desconocen las particularidades propias de distintas realidades políticas, económicas y culturales. En consecuencia, en cada oportunidad en que los regionalismos latinoamericanos se han visto afectados por reveses, disensos entre sus miembros o retrocesos en el proceso colectivo, la búsqueda de causales que permitan explicar esos periodos críticos ha girado en torno a la falta de institucionalidad de los esquemas latinoamericanos. En efecto, las actuales dificultades que enfrenta Unasur se interpretan, en algunos casos, desde esta perspectiva. En este sentido, se sostiene que "el modelo intergubernamental e interpresidencialista de Unasur ayudó al avance del proyecto de integración en tiempos de una mayor sintonía ideológica entre gobiernos. Pero en tiempos de polarización ideológica y política, la falta de una institucionalidad supranacional limita las capacidades de gestión de crisis". ${ }^{19}$

Por otro lado, si retomamos el concepto de $\operatorname{Haas}^{20}$ de integración regional se observa que “incluye el ‘cómo' y el 'por qué' Estados nacionales voluntariamente se reúnen entre sí con sus vecinos con el objetivo de ceder atributos de soberanía, al mismo tiempo que adquieren nuevas capacidades para resolver conflictos entre ellos". ${ }^{21}$ En esta definición, el "cómo"

18 A. Serbin, "Déficit democrático y participación ciudadana en el marco del regionalismo post-liberal", Anuario de Integración Regional de América Latina y el Gran Caribe, A. Serbin, L. Martínez y H. O. Ramazini Jr., Buenos Aires, CrIES, 2012; R. Diamint, "Regionalismo y posicionamiento suramericano: Unasur y ALBA", Revista СІDOB d'Afers Internacionals_(101), 2013, pp. 55-80; A. Malamud, "Overlapping Regionalism, No Integration: Conceptual Issues and the Latin American Experiences", EUI, Working Papers, 2013; Malamud y Gardini, art. cit.

${ }^{19}$ Nolte y Mijares, art. cit.

${ }^{20}$ E. B. Haas, "The study of regional integration: treflections on the joy and anguish of pretheorizing", en L. N. Lindberg y S. A. e. Scheingolds, Regional Integration: Theory and Research, Cambridge, MA, Harvard University Press, 1971.

${ }^{21}$ Ibid, p. 6; Malamud, art. cit., p. 2. 
y el "por qué" implican respectivamente cuestiones metodológicas y de agenda de investigación empírica.

El caso de Sudamérica y el rol de Brasil en los procesos de integración regional nos coloca en un desafío interesante que significa, en gran medida, realizar un esfuerzo heurístico para abrir determinadas "jaulas conceptuales", ${ }^{22}$ es decir, herramientas teóricas que fueron útiles para explicar casos diferentes, pero que se muestran pobres para comprender el fenómeno del regionalismo sudamericano. Por esa razón, en primer lugar, debemos reconocer la existencia de estas "jaulas conceptuales" y, en segundo lugar, reflexionar sobre su superación. Este proceso exige un esfuerzo epistemológico y metodológico importante, para no quedar presos de conceptos y presupuestos del regionalismo y de la integración que nacieron para explicar el origen, evolución y trayectoria de la Unión Europea. Como los autores destacan, el principio central que define la "jaula conceptual" europea sobre lo regional "es la suposición implícita de que la cesión de soberanía o poder nacional a los organismos suprarregionales es la condición sine qua non para la existencia de un proyecto regionalista de integración". 23

Este enfoque restrictivo excluye la consideración de otros aspectos que enriquecen el análisis de un esquema de integración, de forma evolutiva. A modo de ejemplo, ALC comparte valores y normas comunes en materia de pazy seguridad, tales como la solución pacífica de las controversias o la prohibición de armas de destrucción masiva, que son ejemplares si se comparan con cualquier otra región del mundo. En Sudamérica, el proceso histórico regional ha permitido consolidar una zona de paz, donde los países integrantes han dejado de

${ }^{22}$ E. Vivares, P. Torres Lombardo y K. Cvetich, "Enfoques y cárceles conceptuales en el entendimiento de los Nuevos Regionalismos Latinoamericanos", en A. Bonilla y I. E. Álvarez, Desafíos Estratégicos del Regionalismo Contemporáneo: CELAC e Iberoamérica, San José, Costa Rica, Flacso, 2013; E. Vivares, Regionalism, Development and the Post-Commodities Boom in South America, Londres, Palgrave Macmillan, 2018.

${ }^{23}$ Vivares, Torres y Cvetich, art. cit., p. 23. 
lado las rivalidades generando una identificación positiva con el otro. Dicha situación no exime de la presencia de tensiones y desigualdades en la región. No obstante, durante una década, la Unasur demostró capacidad para enfrentar y mediar en una serie de conflictos como las crisis internas de Bolivia en 2008 y de Ecuador en 2010. Asimismo, en 2010 contribuyó a reducir serias tensiones bilaterales entre Colombia y Venezuela. Finalmente, el regionalismo latinoamericano del siglo XXI posibilitó, pese a una considerable rivalidad entre Brasil y México, que dichos gobiernos -dos potencias regionales en pugna- encontraran fórmulas para acomodarse mediante el establecimiento de la CELAC. ${ }^{24}$

En virtud de lo expuesto, es posible identificar otra línea de investigadores ${ }^{25}$ con los cuales coincidimos, y que destacan que los casos latinoamericanos y caribeños responden a "modelos" y/o visiones de la integración regional diferentes. En otras palabras, se trata de un conjunto de perspectivas que, sin caer en un mero parroquialismo, focaliza el análisis en los atributos distintivos del proceso latinoamericano.

Desde este enfoque, un análisis del actual regionalismo latinoamericano pone de manifiesto diversas concepciones yuxtapuestas. La Alianza del Pacífico, por un lado, es una nueva forma de regionalismo abierto, que contrasta con los modelos de regionalismo posliberal y que además ha habilitado cierto regreso de México a Sudamérica. Está constituido

${ }^{24}$ J. A. Vadell, "El Foro China-CELAC y el nuevo regionalismo para un mundo multipolar: desafíos para la Cooperación 'Sur-Sur' ", Carta Internacional 13 (1), 2018, p. 8; Van Klaveren, art. cit.

${ }^{25}$ J. Briceño Ruiz, "La iniciativa del arco del Pacífico latinoamericano: un nuevo actor en el escenario de la integración regional", Nueva Sociedad, 228, 2010, pp. 44-59; P. Riggirozzi, "Re-territorializando...", art. cit. y P. Riggirozzi, "Region, regionness...", art. cit., Riggirozzi y Tussie, op. cit.; J. Briceño Ruiz, "Ejes y modelos en la etapa actual de la integración latinoamericana", Estudios Internacionales, 175; 2013, pp. 9-39; Legler, art. cit.; Malamud, 2013, art. cit., Preciado y Florido, art. cit.; J.A. Sanahuja, "Enfoques diferenciados y marcos comunes en el regionalismo latinoamericano: Alcance y perspectivas de Unasur y CELAC" (pp. 75-108), Pensamento Propio 39, 2014. 
por países que firmaron tratados de libre comercio (TLC) con Estados Unidos, sean éstos bilaterales o plurilaterales, como es el caso del trcan-NAFta. Tres de sus miembros fundadores participan también en la Cooperación Económica de Asia Pacífico (APEC), y dos de ellos (Chile y Perú) tienen TLC con China.

Por otro lado, destacamos las experiencias de regionalismo posneoliberal, como Unasur, ALBA y CELAC. Cabe recordar que el regionalismo posliberal, a diferencia del estructuralismo cepalino tradicional, hace hincapié en las exportaciones, y así la integración tiene un papel central y no de mero soporte al desarrollo nacional: el ámbito internacional se torna entonces importante para la consecución de objetivos nacionales. ${ }^{26}$ En sintonía con los cambios en la orientación de la política externa, el gobierno de Lula buscó profundizar el estrechamiento de vínculos con los países sudamericanos. En un mundo de bloques, Brasil llevó a Sudamérica a fortalecerse como entidad político-económica: "América del Sur surge, entonces, como un polo y una entidad política económica muy importante, a pesar de todas las dificultades que conocemos. El avance de la integración sudamericana, simbolizado por la Unasur, fue un paso importante en esta dirección". ${ }^{27}$

En este contexto, el Mercosur sería un caso "híbrido" y no habría un consenso entre los analistas citados. Creado en 1991, el Mercosur conlleva en sí mismo una contradicción interesante. Su surgimiento se inspiró en los postulados del regionalismo abierto, ${ }^{28}$ como institución para adaptarse a la

${ }^{26}$ Elisa de Sousa Ribeiro Pinchemel, "Paradigmas da atuação brasileira no Mercosul”, Universitas: Relações Internacionais, vol. 9, núm. 1 (2011): 297-330.

27 "A América do Sul surge, então, como um polo e uma entidade político-econômica muito importante, apesar de todas as dificuldades que conhecemos. O avanço da integração sul-americana, simbolizado pela unasul, foi um importante passo nessa direção" [en el texto, traducción del editor], C. Amorim, "Brasil, um país provedor de paz", Estudos Internacionais 1 (2), 2013, pp. 127-138.

28 Comisión Económica para América Latina, CEPAL, El regionalismo abierto en la América Latina y el Caribe. La integración económica al ser- 
globalización neoliberal. No obstante, su propósito normativo fue avanzar hacia una unión aduanera o un mercado común, inspirándose en el modelo de la Unión Europea. Traspasando gobiernos con distintas orientaciones ideológicas, desde aquellos más liberales de la década de los noventa hasta los denominados progresistas de principios del siglo xxI, el Mercosur logró consolidarse como principal esquema de negociación regional de Sudamérica.

El escenario actual, sin embargo, está planteando serios desafíos. En términos económicos, la reciente firma del tratado Mercosur-Unión Europea podría interpretarse como un avance para este esquema regional mercosureño. En cuanto al aspecto político, no obstante, su situación es crítica si tomamos en consideración la existencia de miembros suspendidos (Venezuela) o con riesgo de suspensión (Bolivia) en función de la llamada cláusula democrática. A ello deben sumarse las inminentes tensiones bilaterales entre el gobierno de Bolsonaro y el flamante gobierno electo de Alberto Fernández en Argentina.

La CELAC, por otra parte, se presentaba como el interlocutor y la plataforma natural de los países de ALC, como componente político (y geopolítico) estratégico e intergubernamental del proceso de integración regional. ${ }^{29}$ Este componente es crucial para facilitar la realización de acuerdos económicos extrarregionales con una orientación más autonomista. Los acuerdos con la Unión Europea ${ }^{30}$ y con la República Popular China (RPC) son los acontecimientos destacados de este proceso. ${ }^{31}$

Como contrapartida, en marzo de 2019, los gobiernos de Chile, Colombia, Argentina, Brasil, Ecuador, Paraguay y Perú

vicio de la transformación productiva con equidad, 1994, https:/ / reposito rio.cepal.org/handle/11362/22634

${ }^{29}$ O. Dabène, The politics of regional integration in Latin America : theoretical and comparative explorations, Nueva York, Palgrave Macmillan, 2009.

30 J.A. Sanahuja, "La UE y CELAC: Revitalización de una relación estratégica”, Relaciones birregionales/Series de los Foros de Reflexión, 2015.

31 Vadell, 2018, art. cit. 
decidieron crear el Foro para el Progreso de América del Sur (Prosur). Esta nueva iniciativa de integración regional, de orientación conservadora, nació sobre las cenizas de Unasur, la cual fue abandonada por los nuevos gobiernos que llegaron al poder en los países sudamericanos, considerándola un esquema en exceso ideologizado. Prosur nació con el mismo espíritu que la Alianza del Pacífico, es decir, bajo la promesa de poca burocracia, una estructura simple, sin secretariado y a bajo costo. ${ }^{32}$

En suma, y pese a todas sus limitaciones, ALC ha exhibido "considerables grados de interacción entre unidades políticas (subnacionales, nacionales o transnacionales) que comparten ideas comunes, establecen objetivos y definen métodos para alcanzarlos y, de esa manera, contribuyen a construir una región". ${ }^{33}$ El desorden institucional del regionalismo latinoamericano no debe confundirse con la ausencia de regímenes regionales. ${ }^{34}$ Antes bien, lo que se observa en la actualidad son esquemas regionales en pugna con miradas ideológicas divergentes. Las recientes crisis político-institucionales desencadenadas en Chile y Bolivia parecen haber acentuado dicha polarización.

Pese a ello, destacamos que el proceso colectivo latinoamericano ha evolucionado a partir de dos fuertes tradiciones históricas y legales que, de un lado, abogan por una férrea defensa de la soberanía nacional pero que, al mismo tiempo, exhortan a una solución pacífica de las controversias. Ambos principios han forjado las características distintivas del regionalismo latinoamericano imprimiéndole su singularidad.

La disruptiva llegada de Jair Bolsonaro a la presidencia en Brasil podría echar por tierra los esfuerzos brasileños de conducción sudamericana, lo cual amerita el análisis del rol de Brasil en los regionalismos latinoamericanos.

32 Sáez Leal, J. y F. Rivas Molina, "Sudamérica entierra a la Unasur de Chávez, Kirchner y Lula", El País, 22 de marzo de 2019, https://elpais. com/internacional/2019/03/22/argentina/1553281368_627367.html

${ }^{33}$ Dabène, op. cit., p. 215.

${ }^{34}$ Van Klaveren, art. cit. p. 71. 
POLÍTICA EXTERIOR BRASILEÑa Y REgIONALISMO: ¿América Latina o América del Sur?

\section{Década del noventa: el liderazgo brasileño en el marco de la globalización}

La literatura de política exterior brasileña identifica tres patrones de acción de la política exterior, salvaguardando el interés nacional para ampliar los márgenes de autonomía y estimular el desarrollo. El primero, que prevaleció en las décadas de los sesenta y setenta, es conocido como "autonomía por la distancia" 35 que, básicamente, consistió en posiciones críticas en relación con el statu quo global y se adhirió activamente a las políticas orientadas a la industrialización. Partiendo del presupuesto de que el sistema internacional es jerárquico -centro-periferia- y basado en relaciones de poder asimétricas, se proponían diferentes estrategias para incrementar la autonomía utilizando recursos tangibles e intangibles de poder. Estas estrategias incluían políticas que fomentaran la integración regional o subregional, un mayor equilibrio frente a Estados Unidos y un perfil activo en política exterior. Fue precisamente en este periodo que Brasil y los otros países de ALC intentaron implementar el proyecto del ALALC como un medio de establecer un gran mercado para desarrollar las economías de escala y, por lo tanto, fortalecer las economías nacionales. ${ }^{36}$

35 G. Fonseca Jr, A legitimidade e outras questões internacionais: poder $e$ ética entre as nações, São Paulo, Paz e Terra, 1998

${ }^{36}$ M. R. S. d. Lima, The political economy of Brazilian foreign policy: nuclear energy, trade, and Itaipu, tesis de doctorado, Vanderbilt University, 1986; R. Russell y J. G. Tokatlian, El lugar de Brasil en la política exterior argentina, Buenos Aires, Fondo de Cultura Económica, 2003; J. Estay, "Past and Present of Latin American Regionalisms, in the Face of Economic Reprimarization", en E. Vivares, Regionalism, Development and the Post-Commodities Boom in South America, Londres, Palgrave Macmillan, 2018. 
El segundo patrón de política exterior brasileña es el denominado "autonomía por la integración", ${ }^{37}$ que es muy diferente al concepto de integración trabajado por autores del regionalismo. Esta política, adoptada en la década del noventa, favoreció la apertura económica en curso bajo los postulados del Consenso de Washington. ${ }^{38}$ En este sentido, implicó la búsqueda de una autonomía vía la integración con los mercados globales, en consonancia con la apertura financiera y comercial. Con el fin de la Guerra Fría y la consiguiente supremacía económica, ideológica y militar de Estados Unidos, los responsables de formular la política exterior de Brasil, y de la mayoría de los países de la región, entendían que el país debería participar activamente junto a las potencias económicas occidentales, Estados Unidos en particular, con el objetivo de crear un ambiente favorable para el desarrollo económico. ${ }^{39}$ Bajo esta perspectiva, dicho progreso económico se daría como consecuencia de una apertura amplia y unilateral del comercio y las finanzas. Según la interpretación de muchos académicos, técnicos, políticos y analistas, ésta sería la mejor estrategia de inserción internacional en un mundo regido por la globalización económica. Esta política exterior estaba en sintonía con la visión de un regionalismo liberal o regionalismo abierto, como lo presentaba la CEPAL, ${ }^{40}$ y lo re-

37 El término "autonomía por la participación” también es utilizado en la literatura especializada como sinónimo de "autonomía por la integración”. Fonseca Jr., op. cit., L. Pinheiro, “Traídos pelo Desejo: Um Ensaio sobre a Teoria e a Prática da Política Externa Brasileira Contemporânea”, Contexto Internacional 22 (2), 2000, pp. 305-335; T. Vigevani, M. F. d. Oliveira y R. Cintra, "Política Externa no Periodo FHC: a busca de autonomia pela integração", Tempo Social 15, 2003, pp. 31-61.

$38 \mathrm{~J}$. Williamson, "What Washington means by policy reform", en J. Williamson, Latin American Adjustment: How Much Has Happened?, Washington, Institute for International Economics, 1990.

39 J. Vadell, "La Argentina de Kirchner: el retorno del Estado en el siglo XXI y sus implicaciones en la política externa”, Análise de Conjuntura opsa, 2008, pp. 1-21.

${ }^{40}$ CEPAL, op. cit. 
comendaban fuertemente las instituciones financieras internacionales como el FMI y el Banco Mundial.

En este contexto, el gobierno brasileño de Collor de Mello (1990-1992) fue uno de los promotores, junto con el presidente Carlos Menem, de Argentina, de la creación de un mecanismo de integración del Cono Sur, es decir, del Mercosur. Es menester señalar que, desde sus comienzos, la evolución económica de Brasil, así como sus políticas internas y su posición negociadora dentro del bloque, condicionaron notablemente la marcha global del proceso de integración, su metodología y su agenda de negociaciones. Paralelamente, la actitud brasileña respecto a las negociaciones externas del bloque, por ser el socio mayor, definieron lo que se identifica como "posición Mercosur". ${ }^{41}$

Los comienzos del siglo xxI estuvieron marcados por cambios en la política exterior brasileña en respuesta a un contexto internacional crítico. Los ataques terroristas del 11 de septiembre de 2001 reorientaron las prioridades de política exterior de Estados Unidos, relegando a América del Sur a un segundo plano en las prioridades geopolíticas de la superpotencia. Este hecho y la crisis económica de 2001 -cuyo impacto en la subregión fue particularmente dramático en la Argentina- colocaron en jaque al modelo de política externa basado en la "autonomía por la integración". ${ }^{42}$

\section{Inicios del siglo XXI: la búsqueda de un liderazgo sudamericano}

La crisis económica de inicios de siglo puso en cuestión los principios del modelo de desarrollo neoliberal en la región. De esta manera, la política exterior brasileña, en los últimos años del mandato de Fernando Henrique Cardoso (FHC), mostró algunas tentativas de distancia sutil en relación con

${ }^{41}$ P. d. Motta Veiga, "Brasil, el Mercosur y el ALCA", Foreign Affairs en español, 1, 2001.

42 Vigevani, Oliveira y Cintra, art. cit. 
Estados Unidos, observadas en el trato que se dio a las negociaciones en torno del Área de Libre Comercio de las Américas (ALCA), en la intensificación del diálogo entre el Mercosur y la Unión Europea y, finalmente, en la mayor aproximación con los demás países de Sudamérica, India, la RPC y Sudáfrica.

La elección de Luiz Inácio Lula da Silva como presidente de Brasil significó, en este sentido, la consolidación de esa orientación de cambios que ya había sido tibiamente implementada en el final del gobierno de FCH. Según analistas, inclusive considerando el mandato completo de FCH, la política externa de Lula no presentó muchas diferencias en relación a las temáticas principales.

Si bien desde el punto de vista discursivo, el gobierno del PT se esforzó en enfatizar las diferencias con la anterior administración, en la práctica no existieron cambios radicales en la consecución de la política exterior sino, fundamentalmente, modificaciones o ajustes en las prioridades y en las relevancias otorgadas a las diversas cuestiones. Aun cuando estos dos gobiernos representaban tradiciones diplomáticas diferentes, ambos persiguieron el mismo objetivo distintivo de la política exterior brasileña: desarrollar económicamente al país preservando al mismo tiempo cierta autonomía política. ${ }^{43}$

Desde una perspectiva más minuciosa, Amaury de Souza ${ }^{44}$ diferencia dos corrientes de pensamiento, cada una de las cuales proponía determinadas estrategias para la inserción internacional de Brasil. La primera corriente, de corte liberal, se aproximaba a los supuestos y directrices que guiaron la política exterior de Brasil durante el gobierno de FHC. Promovía la realización de reformas internas tendientes a fortalecer las reglas de mercado en la economía doméstica. La autonomía

${ }^{43}$ C. Giaccaglia, "Brasil desde la mirada argentina. El activismo internacional brasileño en los ámbitos multilaterales", en R. Bernal Meza y L. Bizzozero, La política internacional de Brasil: de la región al mundo, Montevideo, Ed. Cruz del Sur, 2014, p. 81.

${ }^{44}$ Amaury de Souza, A agenda internacional do Brasil. A política externa brasileira de fhc a Lula, Río de Janeiro, CEBRI, 2009. 
nacional se procuraba mediante la cooperación para la creación de regímenes internacionales que mejorasen las posiciones negociadoras frente a los países más fuertes. ${ }^{45}$ En el otro extremo, se encontraban los críticos de la agenda de liberalización, muchos de los cuales comandaron la política exterior ejecutada por el gobierno de Lula da Silva. Esta estrategia defendía la inserción mundial de Brasil por medio de un proyecto nacional autónomo, basado en activas políticas de desarrollo y en la creación de alianzas con países que tuviesen intereses semejantes, es decir, la cooperación Sur-Sur (css) y la profundización de la integración de Sudamérica. Dicha estrategia se proponía contribuir al surgimiento de un orden internacional multipolar que contuviese las políticas unilaterales estadounidenses, distintivas de los primeros años post 11-S. ${ }^{46}$

En función de esta última estrategia mencionada y conforme fueron avanzando los años de la gestión del PT en el poder, fue posible observar ciertas reorientaciones en la manera de actuar y en las posiciones en los foros internacionales. El gobierno Lula asumió una postura más crítica respecto a los efectos de la globalización, reafirmando las posiciones tradicionales de Brasil en las negociaciones comerciales para obtener acceso a los mercados de los países industrializados, defendiendo mecanismos que favorecieran a las naciones menos desarrolladas y la implementación de políticas de desarrollo que permitiesen una mayor autonomía tecnológica. Así, aplicando una estrategia de "autonomía por la diversificación", ${ }^{47}$ el gobierno de Lula se adhirió a los principios, normas y reglas internacionales, propiciando mayores niveles de multilateralismo internacional, enfocándose en las alianzas Sur-Sur, que incluían tanto a las alianzas regionales estrechas como con Argentina -dando continuidad a la prioridad que había definido FCH-, así como los

45 Ibid., p. 21.

${ }^{46}$ Ibid., pp. 22-23.

${ }^{47}$ T. Vigevani y G. Cepaluni, "A Política Externa de Lula da Silva: A Estratégia da Autonomia pela Diversificação", Contexto Internacional 29 (2), 2007, pp. 273-334. 
acuerdos con socios no tradicionales, como la RPC, India, Rusia, varios países de África y el Oriente Medio.

De esta manera, una vez consolidado el poder del PT a nivel nacional, fue posible diferenciar tres corrientes principales de pensamiento en materia de política exterior. ${ }^{48} \mathrm{En}$ primer lugar, los globalistas: aquellos que continuaban defendiendo las medidas de liberalización como medio para insertarse al mundo, creían que Brasil debía seguir fortaleciendo sus vínculos comerciales con los países desarrollados del norte y que la integración regional debía concentrarse en el comercio, las inversiones y la infraestructura. Este primer grupo se constituyó entonces en el sector de los grandes críticos del gobierno de Lula.

En segundo lugar, se hallaban los posliberales, que cuestionaban la actual distribución del poder mundial y, por consiguiente, privilegiaban la css mediante el establecimiento de alianzas horizontales tanto con los países sudamericanos como con las potencias emergentes extrarregionales. Los posliberales fueron el sector más favorable al gobierno de Lula y se ubicaron, fundamentalmente, en torno de las políticas desarrolladas por Celso Amorin, diplomático de carrera y ministro de Relaciones Exteriores de ese gobierno.

Por último, se encontraban los regionalistas, que ponían el énfasis en la integración regional como base para una posterior integración a la economía mundial. En este sentido, consideraban que la proyección global brasileña dependía de la capacidad de poder, en primer lugar, integrar el continente sudamericano. A diferencia de los posliberales, este grupo estimaba que el país no podía conquistar, por sí solo, la proyección deseada en la escena internacional. ${ }^{49}$ Los regionalistas se agruparon fundamentalmente en torno a la figura de Marco Aurelio García, miembro del PT y principal asesor de Lula para asuntos latinoamericanos. 
En función de la situación descrita, cabe remarcar la actuación del propio Lula da Silva quien, sobre la base de una eximia diplomacia presidencial, supo conjugar las acciones desarrolladas tanto en ámbitos regionales como globales, con cierta cuota de ambigüedad, pero sin provocar fricciones de importancia, sobre todo en relación con los países de su vecindario. ${ }^{50}$

Como destacan Mariano, Ramanzini Junior y Ribeiro de Almeida, con el gobierno Lula hubo un foco en la dimensión política de la política externa brasileña y un énfasis en la autonomía regional y nacional "fruto de la percepción de que la integración y la cooperación regional exigen determinadas acciones que las fuerzas del mercado por sí solas no son capaces de realizar". ${ }^{51}$

En lo que respecta al fortalecimiento del Mercosur, en octubre de 2003, los presidentes Lula y Néstor Kirchner firmaron el "Consenso de Buenos Aires" en la capital argentina, comprometiéndose en temas como desarrollo de tecnología, participación conjunta en diversos foros internacionales, la negociación del ALCA, el medio ambiente y la gestión de la deuda pública. Durante este periodo, las relaciones en el Mercosur se caracterizaron por diversos conflictos sectoriales, disputas comerciales y discusiones predominantemente bilaterales argentino-brasileñas. Si bien se registraron ciertos intentos para superar estos problemas y avanzar en la profundización de la integración -como la implementación del FOCEM, las iniciativas para eliminar el doble cobro del arancel externo común (AEC) y los programas y proyectos con vistas a la integración en las principales cadenas productivas de la región- los resultados no fueron significativos.

${ }^{50}$ G. Lechini y C. Giaccaglia, "Brasil en el laberinto de los espejos. Su rol regional en el siglo xxi”, El debate político, revista iberoamericana de análisis político, 4 (6), 2007, pp. 70-87.

${ }^{51}$ M. P. Mariano, Ramanzini Júnior, H. y Ribeiro de Almeida, R. A., "O Brasil e a Integração na América do Sul. Uma Análise dos Últimos Dez Anos”, Relações Internacionais (41), 2014, p. 123. 
La convergencia política e ideológica de ambos gobiernos sudamericanos no viabilizó la profundización del Mercosur, como bien lo destacan Vigevani, Favaron, Ramanzini y Correia. ${ }^{52}$ Esto se debió, sobre todo, a los desequilibrios comerciales entre Argentina y Brasil y a las respuestas del gobierno argentino, en algunos casos unilaterales, que evidenciaron los conflictos de intereses en la dimensión de la economía sectorial. ${ }^{53}$ La rápida recuperación argentina tuvo como consecuencia directa alteraciones sustanciales en el comercio bilateral con Brasil, creando un creciente déficit en la balanza comercial argentina que llegó a más de 3600 millones de dólares en 2005. En 2008, el déficit argentino llegó a la cifra de 4400 millones de dólares con Brasil. Los conflictos bilaterales tenían, por lo menos, un motivo comercial visible. ${ }^{54}$ El recrudecimiento de este problema fue una constante en la década y media del siglo Xxi. Según el Instituto de Estadísticas y Censos de la Argentina (INDEC), el déficit comercial con Brasil en 2016 fue de US\$ 4566 millones y en 2017 fue de US\$ 8563 millones. ${ }^{55}$

Los conflictos entre Argentina y Brasil, centrados en las cuestiones comerciales, han pautado las principales discusiones entre ambos países en los últimos años, evidenciando el carácter comercial e intergubernamentalista de esa fase del modelo de integración del Mercosur. Desde 2005, el gobierno argentino presionaba a Brasil para la aplicación de las cláusulas de salvaguardas para algunos sectores de la industria argentina, hasta que, en febrero de 2006, logró una con-

52 T. Vigevani, G. Favaron, H. Ramanzini y R. A. Correia, "O Papel da Integração regional para o Brasil: universalismo, soberania e percepção da elites”, Revista Brasileira de Política Internacional, 51 (1), 2008, p. 19.

${ }^{53}$ T. Campos y J. Vadell, "A Encruzilhada Regional do Mercosul: Brasil e a Argentina na procura de um relacionamento estável para o século XXI", OPSA, Análise de Conjuntura, 2009.

${ }^{54}$ En 2002, año posterior a la crisis, el superávit comercial de Argentina había sido de más de 2300 millones de dólares, según datos consultados de la ALADI, http://nt5000.aladi.org/siicomercioEsp/MarcoInferior.htm

${ }^{55}$ INDEC, op. cit. 
quista significativa. Ambos países llegaron a un acuerdo con la creación de un Mecanismo de Adaptación Competitiva ${ }^{56}$ (MAC), cuya función sería evitar la entrada predatoria de productos de uno de los dos países al mercado vecino. De esta manera, "las críticas a esa negociación fueron expresivas por parte de sectores del propio gobierno brasileño, especialmente del Ministerio de Hacienda, el Ministerio de Planificación y el de Industria y Comercio". ${ }^{57}$ En aquella época, la prensa brasileña destacó: "A pesar de ser extremadamente celebrado desde el lado argentino y entendido por el grupo de los responsables de tomar decisiones de Itamaraty (cancillería brasileña) como esencial para la sobrevivencia del bloque, el acuerdo provocó descontento en el sector productivo brasileño y generó discordias incluso en el interior del gobierno". 58

Los sectores industriales brasileños también se mostraron contrarios al acuerdo. El entonces presidente de la Confederación de la Industria (CNI), Armando Monteiro Neto, expresó que "el mecanismo contraría el espíritu de la integración del Mercosur y genera un clima de retroceso en el desarrollo

${ }^{56}$ Este mecanismo fue creado en 2005 para superar las divergencias comerciales entre Argentina y Brasil; establece salvaguardas comerciales para ciertos productos con el objetivo de satisfacer la demanda de algunos sectores económicos de Argentina y de Brasil (pero especialmente de Argentina), que se sentían amenazados por la baja competitividad de los productos, en el caso de que se aplicasen los mecanismos de una unión aduanera completa. A pesar de haber generado reacciones negativas del lado brasileño, la iniciativa fue un paso importante para preservar las relaciones bilaterales y estimular consenso en otras temáticas, tales como el acuerdo automotriz y la desdolarización del comercio bilateral.

57 Campos y Vadell, art. cit.

58 "Embora extremamente comemorado pelo lado argentino e entendido pelo grupo decisório do Itamaraty como essencial à sobrevivência do bloco, o acordo provocou descontentamento entre o setor produtivo brasileiro, sendo motivo de discórdia até mesmo dentro do governo" [traducción en texto del editor], "Acordos e Discussões", Diario O Globo, 3 de febrero de 2006, http:/ / g1.globo.com/bomdiabrasil/0,,MUL815454-1602 0,00-ACORDO+E+DISCUSSOES.html 
del bloque" ${ }^{59}$ En la misma sintonía, el presidente de la Federación de Industrias de São Paulo (FIESP), expresó:

Si hubiera desvío de comercio, éste fortalecería la industria china, la coreana, la de Indonesia, pero no la industria argentina. Tal y como está escrito, no impide ni elimina la posibilidad de desvío de comercio. En la práctica, se observa que a lo largo de estos años, incluso en estos acuerdos sectoriales, en muchos casos terminaron dando lugar a un desvío de comercio. En otras palabras, Argentina dejando de comprar a Brasil y comprando a países de otros continentes. ${ }^{60}$

Este momento, quizás, haya sido el más interesante para observar la división de fuerte carácter antiintegracionista en importantes sectores de la burguesía empresarial brasileña. Estos segmentos empresariales comenzaron a exteriorizar sus desagrados respecto al Mercosur, expresando que lo más conveniente sería un retroceso real y estratégico. Es decir, consolidar solamente una zona de libre comercio, situación que permitiría a Brasil firmar acuerdos comerciales bilaterales con otros países. Este repliegue, fundamentan sus defensores, reforzaría la autonomía del país.

Lima $^{61}$ reconoce que la alianza estratégica de Brasil ${ }^{62}$ con Argentina se vio perjudicada por la erosión de las coaliciones domésticas de los sectores favorables a la integración, tanto entre los sectores pro apertura económica como entre los desarrollistas. Sin embargo, este descontento, como apuntan Vigevani et al., ${ }^{63}$ ya se manifestaba en 2004, cuando se produce la coincidencia de posiciones entre la FIESP, Abical-

${ }^{59}$ Loc. cit.

${ }^{60}$ Loc. cit., traducción del editor.

61 M. R. S. d. Lima, "Decisões e indecisões: um balanço da política externa do primeiro governo do presidente Lula”, Observatório Político SulAmericano, 2007.

${ }^{62}$ M. R. S. d. Lima, "Tradição e Inovação na Política Externa Brasileira”, Plataforma Democrática, 2010.

${ }^{63}$ Vigevani, Favaron, et al., p. 19. 
çados (Asociación brasileña de fabricantes de calzados), Eletros (Asociación nacional de fabricantes de productos electrónicos) y la AEB (Asociación brasileña de comercio exterior). Las raíces de este encuentro pueden hallarse en la década de los noventa, cuando "los intereses brasileños comenzaron a movilizarse y crearon una Coalición Empresarial Brasileña (СЕB) con el objetivo de establecer posiciones consensuales entre los diversos sectores en las negociaciones del Mercosur".

Frente a estas desavenencias ocurridas en torno al Mercosur, el gobierno brasileño de Lula da Silva efectuó el lanzamiento de una nueva iniciativa en el marco de los regionalismos latinoamericanos, a partir de la creación de Unasur. Dicho proyecto buscó consolidar el liderazgo brasileño en todo el continente sudamericano. Por esta misma razón, el gobierno argentino de Néstor Kirchner se mostró reticente, en un principio, a este proyecto que fue, sin embargo, aceptado más tarde, con cierta "resignación" por el gobierno de Cristina Fernández de Kirchner frente al inevitable ascenso brasileño.

Las dos primeras décadas del siglo xxi constituyeron, por tanto, una etapa de consolidación del liderazgo del gigante sudamericano en la región, en la medida en que fue capaz de neutralizar esquemas integracionistas alternativos -como el ALCA, propuesto por Estados Unidos, y el ALBA, de Hugo Chávez- y de excluir otros posibles liderazgos regionales como el mexicano, logrando imponer su propio proyecto de una unidad geopolítica y económica sobre la base de las fronteras sudamericanas. Pasada esta primera etapa de integración, las sintonías político-ideológicas del eje Brasilia-Buenos Aires-Caracas, propiciaron una reafirmación de Unasur como principal interlocutor de la región con el resto del mundo, basados además en una agenda que trascendía lo meramente económico-comercial.

No obstante, las asimetrías existentes con Brasil siguieron siendo el principal factor disruptivo. En la última década del siglo xx, los dos mercados principales del Mercosur se tornaron muy interdependientes en términos comerciales y 
de flujo de capitales, pero esta dependencia fue mayor para Argentina que para Brasil, cuyas exportaciones se diversificaron hacia otras regiones. ${ }^{64}$ En este mismo sentido se observa que el mercado brasileño recibió una significativa porción de las ventas externas argentinas, constituyéndose en el principal comprador mundial de bienes de Argentina y superando holgadamente tanto a Chile como a China. No obstante, su importancia comparativa como mercado de destino de la producción argentina fue mermando perceptiblemente. Este descenso obedece, especialmente, al incremento de las ventas argentinas a China, Estados Unidos y otros países de ALC. ${ }^{65}$ Como contrapartida, el histórico segundo puesto ocupado por Argentina (detrás de Estados Unidos) como el segundo comprador internacional de Brasil también se vio modificado por el crecimiento de China en la región, que desplazó a Argentina a partir de 2009. ${ }^{66}$

Los esfuerzos brasileños de consolidación del esquema regional no lograron sostenerse en el tiempo y cuando la situación interna comenzó a deteriorarse, ésta tuvo como correlato el inicio de una fase también crítica para las iniciativas regionales. Si bien es cierto que la crisis brasileña no es el único factor a tener en cuenta, puesto que a ella se suma la grave situación interna de Venezuela, así como la renovada incertidumbre económico-financiera de Argentina, lo cierto es que la actual vulnerabilidad del principal articulador del

${ }^{64} \mathrm{~V}$. Klagsbrunn, "Argentina e Brasil: relações comerciais em expansão no âmbito do MERCOSUL”, en G. Lechini, W. Gonçalves y V. Klagsbrunn, Argentina e Brazil. Vencendo os preconceitos. As várias arestas de uma concepção estratégica, Río de Janeiro, Revan, 2009, pp. 425-430.

${ }^{65}$ Cámara Argentina de Comercio y Servicios, "Las exportaciones argentinas: evolución reciente y caminos para su expansión”, Buenos Aires, CAC: 2016, https://www.cac.com.ar/data/documentos/1_CAC\%20Las\% 20exportaciones\% 20argentinas\%20-\% 20Evoluci\%C3\%B3n\%20reciente \%20y\%20caminos\%20para\%20su\%20expansi\%C3\%B3n.pdf

${ }^{66} \mathrm{~S}$. Schtremel, La "alianza estratégica" argentino-brasileña en el proceso de conformación de un subsistema internacional sudamericano. Lexis y praxis en la política externa brasileña hacia la Argentina, tesis doctoral, Universidad Nacional de Rosario, 2018, p. 124. 
proceso regional debilita el esquema sudamericano en su conjunto.

La crisis brasileña de 2016: preludio de la fragmentación sudamericana

Con la llegada de Michel Temer, las grandes estrategias desarrolladas por los gobiernos del PT se mantuvieron en los ámbitos globales por medio de políticas reactivas o de acompañamiento -como en el caso de BRICS- mientras que en las esferas regionales se optó por una desactivación de ciertas iniciativas -como la suspensión de actividades en el caso de Unasur- o por la búsqueda de una flexibilización de los esquemas, como la que se pretende en el ámbito del Mercosur. ${ }^{67}$

Al llegar Temer al poder con una agenda conservadora, coincidió con un movimiento regional de retroceso de los gobiernos progresistas en la región. Desde el segundo mandato de Dilma Roussef y, especialmente, con Michel Temer, la política externa brasileña fue reactiva, contradictoria y confusa. Durante la primera fase, a inicios del gobierno de Temer, se intentó desarticular la idea de "golpe" frente al proceso de impeachment. En la segunda fase, con José Serra del partido PSDB como Ministro de Relaciones Exteriores, se buscó implementar un programa específico basado en 10 directrices. ${ }^{68}$ De estos puntos, dos objetivos se destacaron en la nueva agenda conservadora y se extendieron hasta la visión de mundo sostenida por el actual gobierno de Bolsonaro: 1) la entrada de Brasil a la Organización para la Cooperación y Desarrollo Económico (OCDE), y 2) la aceleración de la negociación del

${ }^{67}$ C. Giaccaglia, "Brazil: ladders and snakes", Janus.net, E-journal of International Relations 9 (1), 2018, p. 164.

${ }^{68} \mathrm{~J}$. Serra, Discurso do ministro José Serra por ocasião da cerimônia de transmissão do cargo de ministro de estado das Relações Exteriores, 2016, http:/ / www.itamaraty.gov.br/pt-BR/notas-a-imprensa/14043-discurso-doministro-joseserra-por-ocasiao-da-cerimonia-de-transmissao-do-cargode-ministro-de-estado-dasrelacoes-exteriores-brasilia-18-de-maio-de-2016 
acuerdo Mercosur y Unión Europea. Estos dos focos fueron ganando importancia en la política doméstica, en especial para legitimar las políticas económicas de austeridad en tres proyectos específicos: a) el proyecto de enmienda constitucional de límites de gastos públicos (PEC do teto de gastos) que congeló los gastos públicos por 20 años; 2) la reforma laboral y 3) la reforma del sistema jubilatorio y de pensiones, ${ }^{69} \mathrm{el}$ cual fue demorado pero logró aprobación en octubre de 2019, ya durante el gobierno de Bolsonaro.

En marzo de 2017, Aloísio Nunes, también del PSDB, reemplazó a José Serra como canciller, manteniendo las mismas directrices en materia de política exterior. No obstante, la inestabilidad política y la escasa legitimidad del gobierno de Temer hicieron imposible avanzar con una agenda propositiva. Con respecto a la ocDE, la idea de Temer y las elites económicas era colocar a Brasil en el "club de los países ricos", pero esa intención enfrentó fuertes resistencias, en especial de Estados Unidos. Esta reticencia se manifestó posteriormente durante el gobierno Bolsonaro, de clara posición pro Estados Unidos, como una ingrata sorpresa, cuando en octubre de 2019 el gobierno de Trump escogió a Argentina y Rumania como candidatos a la OCDE. ${ }^{70}$

El foco de preocupación política fue puesto entonces en la consecución de una agenda "negativa" la cual tuvo continuidad durante los primeros meses del gobierno de Bolsonaro. La acción más destacada en este sentido fue la declaración conjunta de Brasil, Argentina, Paraguay, Colombia, Perú y Chile, el 20 de abril de 2018, de suspender, por tiempo indeterminado la participación de sus gobiernos en Unasur, antesala del retiro definitivo realizado por Argentina y seguido por el gigante sudamericano bajo la gestión de Bolsonaro en

69 "Reforma da Previdência".

70 "Leia a íntegra da carta em que os EUA recomendam apenas Argentina e Romênia para a ocDE", Folha de São Paulo, 11 de octubre de 2019, https://www1.folha.uol.com.br/mercado/2019/10/leia-a-integra-da-car ta-onde-o-eua-recomenda-apenas-argentina-e-romenia-para-a-ocde.shtml 
abril de 2019. De esta manera, se concretó, una virtual extinción de Unasur.

En materia de política regional, la visión conservadora que comparten los gobiernos de Temer y Bolsonaro indica, en gran medida, un retorno a la idea de regionalismo abierto y el enfoque subyacente de pensar los procesos de integración regional, no como una herramienta de autonomía y proyección internacional de Brasil, más o menos institucionalizada, sino como un estorbo con los objetivos de alineación automática con Estados Unidos y para integrarse a la economía global de manera unilateral. Esa concepción "antirregional" puede observarse desde el inicio del gobierno Temer, con su canciller José Serra, hasta los primeros meses del gobierno de Bolsonaro, con el canciller Ernesto de Araujo.

En suma, la estrategia brasileña de liderazgo sudamericano ha sido dinamitada en menos de un año. Al abandono de Unasur, se añade un malestar creciente en la relación bilateral con Argentina, producto de la inminente llegada del gobierno de Alberto Fernández. Esta tensión en la relación argentino-brasileña, que es clave para el futuro regional, ha tenido dos manifestaciones. Por un lado, el interés del gobierno bolsonarista de propiciar una reducción del arancel externo común en el seno del Mercosur, lo cual podría generar serias consecuencias para la economía argentina y que, por consiguiente, cuenta con el rechazo del próximo gobierno de Alberto Fernández. En segundo lugar, las reiteradas fricciones entre Bolsonaro y Fernández han promovido un regreso de México a nuestra región, de la mano de Argentina, lo cual erosiona la idea de "Sudamérica" y vuelve a potenciar una visión amplia de "Latinoamérica" que durante tanto tiempo Itamaraty intentó evitar.

\section{Conclusiones}

Como pudimos observar a lo largo de este trabajo, el regionalismo ha constituido uno de los ejes centrales de las rela- 
ciones internacionales latinoamericanas y caribeñas. En este contexto, Brasil se constituyó en un protagonista crucial como principal articulador del proyecto integracionista de Sudamérica.

El regionalismo latinoamericano se trata de un proceso añejo, que ha conocido altas y bajas sucesivas, en función de condicionamientos tanto internos como externos. En la actualidad, los procesos regionales se encuentran frente a una nueva encrucijada que, por tanto, no constituye una excepción a la evolución hasta aquí detallada.

En este sentido, la comunidad epistémica ha comenzado a hablar de una nueva etapa de "regionalismo à la carte". ${ }^{71} \mathrm{En}$ este contexto, dicho regionalismo está caracterizado por una desaceleración y profundización de la bilateralización de la integración en ALC, ${ }^{72}$ lo cual puede explicarse tanto por variables exógenas como endógenas.

Desde un punto de vista sistémico, las principales variables a considerar incluyen el auge internacional de políticas proteccionistas y soberanistas, asociadas con el Brexit y la llegada de Donald Trump al gobierno de Estados Unidos, así como la irrefrenable presencia de China en la región -que puede implicar tanto un efecto capitalizador para las economías sudamericanas orientadas a la exportación, como un efecto devastador si sólo conlleva una agudización del proceso de reprimarización que comenzó a afectar a la región durante la última década. La actual guerra comercial sino-norteamerica-

${ }^{71}$ N. Comini y A. Frenkel, "Unasur, de proyecto refundacional al fantasma del Sudamexit", Anuario de la Integración Regional de América Latina y el Gran Caribe, núm. 13, A. Serbin, L. Martínez Alfonso, H. Ramanzini Júnior y A. Serbin Pont, Buenos Aires, Coordinadora Regional de Investigaciones Económicas y Sociales (CRIES), 2016, pp. 181-207. C. Quiliconi, "The South American Regionalisms: A Shift or the Return of Economic Integration?”, en E. Vivares, Regionalism, Development and the Post-Commodities Boom in South America, Londres, Palgrave Macmillan, 2018

${ }^{72}$ Comini y Frankel, p. 182. 
na iniciada en 2019 ha profundizado la fragilidad del comercio internacional con claras repercusiones para América Latina.

En cuanto a los factores endógenos, el actual regionalismo a la carta manifiesta una significativa fragmentación política. Esta fragmentación fue producto, en primer lugar, de diversos cambios de gobierno en la región, acompañados por un estado de abulia generalizado. Posteriormente, la fragmentación se ha profundizado por la presencia de esquemas regionales en pugna, con miradas ideológicas divergentes. A ello se suma una creciente inestabilidad producto del estallido social en Chile y el debatido golpe de Estado en Bolivia. Cabe aclarar, sin embargo, que las desconfianzas y resquemores intragrupo pueden rastrearse con anterioridad, con dos hechos trascendentales: la suspensión de Paraguay luego de la destitución de Fernando Lugo, en 2012, y las discrepancias por la crisis venezolana a partir de 2014.

A ello se suma el avance de la Alianza del Pacífico como esquema alternativo que ha contribuido a reforzar en la región la idea de que es necesaria una flexibilización de los esquemas existentes, como por ejemplo en el Mercosur. "Negociar a velocidades separadas”, así como evitar estar atados a una negociación conjunta frente a terceros países se han convertido en algunas de las principales premisas de esta nueva etapa regional. ${ }^{73}$

En este contexto, la llegada del gobierno de Jair Bolsonaro a Brasil ha significado un quiebre en la tradicional política exterior de este país hacia su esfera de pertenencia, en la medida en que ha dejado de lado el estrechamiento de relaciones regionales en la búsqueda por desacoplar a Brasil de su entorno, a los efectos de propiciar una inserción internacional unilateral con, además, un claro acercamiento a Estados Unidos.

Este vacío ha facilitado la reaparición de México dentro de este proyecto y ha colaborado al retorno de la idea de Latinoamérica como centro neurálgico de la definición

${ }^{73}$ Ibid., p. 196. 
geopolítica del "vecindario", ${ }^{74}$ en detrimento del concepto de Sudamérica.

Una mirada retrospectiva, nos permite ver que el proceso de impeachment a Dilma Rousseff constituyó el origen de una fuente de enfrentamientos entre los países de la región, por la legalidad o ilegalidad del proceso. En otras palabras, el inicio de una crisis político institucional en Brasil, es decir, en el seno del principal articulador de las iniciativas regionales de las últimas décadas, provocó un golpe al corazón del regionalismo sudamericano.

El retraimiento del liderazgo brasileño en Sudamérica, junto con los virajes y desorientaciones ocurridas al interior de Mercosur, la desaparición de Unasur y la creación de nuevas y frágiles iniciativas como ProSur han dañado la credibilidad de las iniciativas de la región, así como la posibilidad de identificar una voz conjunta en Sudamérica, como un todo diferenciado.

\section{REFERENCIAS BIBLIOGRÁFICAS}

Amorim, C., "Brasil, um país provedor de paz", Estudos Internacionais 1 (2), 2013, pp. 127-138.

Bouzas, R., "Las relaciones Unión Europea-Mercosur", Nueva Sociedad, 190, 2004.

Briceño Ruiz, J., "La iniciativa del arco del Pacífico latinoamericano: un nuevo actor en el escenario de la integración regional", Nueva Sociedad, 228, 2010, pp. 44-59.

BRICEÑo Ruiz, J., "Ejes y modelos en la etapa actual de la integración latinoamericana”, Estudios Internacionales, 175; 2013, pp. 9-39.

Buzan, B. y O. WAEver, Regions and powers: the structure of international security, Cambridge, Nueva York, Cambridge University Press, 2003.

${ }^{74}$ Esta noción se refiere a que comenzó a verse a América Latina en su conjunto y no sólo a Sudamérica (que podemos entender con una parte de América Latina) como espacio para forjar relaciones. 
Cámara Argentina de Comercio y Servicios, "Las exportaciones argentinas: evolución reciente y caminos para su expansión", Buenos Aires, CAC: 2016, https://www.cac.com.ar/data/documentos/1_CAC\%20Las\%20exportaciones\%20argentinas\% 20 -\%20Evoluci\% C3\%B3n \% 20reciente $\%$ 20y\% 20caminos\% 20 para\%20su\%20expansi\%C3\%B3n.pdf

Campos, T. y J. Vadell, "A Encruzilhada Regional do Mercosul: Brasil e a Argentina na procura de um relacionamento estável para o século XXI", OPSA, Análise de Conjuntura, 2009.

Cardoso, E. y M. Holland, “¿Sudamérica para los chinos? Un análisis basado en el comercio”, Cuadernos CEALCI, 2010.

Comisión Económica para América Latina, CEPAL, El regionalismo abierto en la América Latina y el Caribe. La integración económica al servicio de la transformación productiva con equidad, 1994, https://repositorio.cepal.org/handle/11362/22634

Cervo, A., "Brazil's Rise on the International Scene: Brazil and the World", Revista Brasileira de Política Internacional, en Amado Cervo y Antônio Carlos Lessa (ed.), Emerging Brazil under Lula: an assessment on International Relations (2003-2010), año 53, edición especial.

Comini, N. y A. Frenkel, "Unasur, de proyecto refundacional al fantasma del Sudamexit", Anuario de la Integración Regional de América Latina y el Gran Caribe, núm. 13, A. Serbin, L. Martínez Alfonso, H. Ramanzini Júnior y A. Serbin Pont, Buenos Aires, Coordinadora Regional de Investigaciones Económicas y Sociales (CRIES), 2016, pp. 181-207.

DABÈne, O., The politics of regional integration in Latin America : theoretical and comparative explorations, Nueva York, Palgrave Macmillan, 2009.

Diamint, R., "Regionalismo y posicionamiento suramericano: Unasur y ALBA", Revista СIDOB d'Afers Internacionals (101), 2013, pp. 55-80.

Estay, J., "Past and Present of Latin American Regionalisms, in the Face of Economic Reprimarization”, en E. Vivares, Regionalism, Development and the Post-Commodities Boom in South America, Londres, Palgrave Macmillan, 2018. 
"Leia a íntegra da carta em que os EUA recomendam apenas Argentina e Romênia para a ocDE", Folha de São Paulo, 11 de octubre de 2019, https://www1.folha.uol.com.br/mercado/2019/ 10/leia-a-integra-da-carta-onde-o-eua-recomenda-apenas-ar gentina-e-romenia-para-a-ocde.shtml

Fonseca JR, G., A legitimidade e outras questões internacionais: poder e ética entre as nações, São Paulo, Paz e Terra, 1998.

Giaccaglia, C., "Brasil desde la mirada argentina. El activismo internacional brasileño en los ámbitos multilaterales", en R. Bernal Meza y L. Bizzozero, La política internacional de Brasil: de la región al mundo, Montevideo, Ed. Cruz del Sur, 2014.

Giaccaglia, C., "Brazil: ladders and snakes", Janus.net, E-journal of International Relations 9 (1), 2018, pp. 155-169.

Lechini, G. y C. Giaccaglia, "Brasil en el laberinto de los espejos. Su rol regional en el siglo xxi", El debate político, revista iberoamericana de análisis político, 4 (6), 2007, pp. 70-87.

HAAs, E. B., "The study of regional integration: treflections on the joy and anguish of pretheorizing", en L. N. Lindberg y S. A. e. Scheingolds, Regional Integration: Theory and Research, Cambridge, MA, Harvard University Press, 1971.

Накім, P., "Two Ways to Go Global”, Foreign Affairs, 81 (1), 2002.

Instituto de Estadísticas y Censos, INDEC, Intercambio Comercial Argentino, Buenos Aires, Argentina, Indec, 2018.

Katzenstein, P. J., A World of Regions, Londres e Ithaca, Cornell University Press, 2005.

Klagsbrunn, V., "Argentina e Brasil: relações comerciais em expansão no âmbito do MERCOSUL”, en G. Lechini, W. Gonçalves y V. Klagsbrunn, Argentina e Brazil. Vencendo os preconceitos. As várias arestas de uma concepção estratégica, Río de Janeiro, Revan, 2009.

Lake, D. A. y P. M. Morgan, Regional orders: building security in a new world, University Park, Pa., Pennsylvania State University Press, 1997.

Legler, T., "Post-hegemonic regionalism and sovereignty in Latin America: optimists, skeptics, and an emerging research agenda”, Contexto Internacional 35 (2) 2013, pp. 325-352. 
Lima, M. R. S. d., The political economy of Brazilian foreign policy: nuclear energy, trade, and Itaipu, tesis de doctorado, Vanderbilt University, 1986.

LIMA, M. R. S. d., "Decisões e indecisões: um balanço da política externa do primeiro governo do presidente Lula", Observatório Político Sul-Americano, 2007.

Lima, M. R. S. d., "Tradição e Inovação na Política Externa Brasileira”, Plataforma Democrática, 2010.

Malamud, A., "Overlapping Regionalism, No Integration: Conceptual Issues and the Latin American Experiences", Eui Working Papers, 2013.

Malamud, A. y G. L. Gardini, "Has Regionalism Peaked? The Latin American Quagmire and its Lessons", 47, 1, 2012, pp. 116-133.

Mariano, M. P., Ramanzini Júnior, H. y Ribeiro de Almeida, R. A., "O Brasil e a Integração na América do Sul. Uma Análise dos Últimos Dez Anos", Relações Internacionais (41), 2014, pp. 123-134.

Miranda, R., Política exterior argentina. Idas y venidas entre 1999 y 2003, Rosario, Ediciones PIA, 2003.

Motta Veiga, P. d., "Brasil, el Mercosur y el Alca", Foreign Affairs en español, 1, 2001.

Nolte, D., "Potencias Regionales en la Política Regional: conceptos y enfoques de análisis”, Working Papers núm. 30, 2006.

Nolte, D. y V. Mijares, "La crisis de Unasur y la deconstrucción de Sudamérica”, Dossier Especial: crisis de Unasur, 2018.

Pereyra Doval, Gisela, La identidad nacional de Brasil en su política exterior. El caso de los gobiernos de Vargas (1930-1945), Geisel (1974-1979) y Da Silva (2003-2010), tesis doctoral, Rosario, Argentina, Universidad Nacional de Rosario, 2011.

Pinheiro, L., "Traídos pelo Desejo: Um Ensaio sobre a Teoria e a Prática da Política Externa Brasileira Contemporânea", Contexto Internacional 22 (2), 2000, pp. 305-335.

Preciado, J. y A. Florido, "La Comunidad de Estados Latinoamericanos y Caribeños: integración 'postneoliberal', neoliberal ortodoxa y contrahegemónica”, en Carlos Eduardo Martins y Consuelo Silva Flores (coord.), Nuevos Desafios para la Integración de América Latina, Buenos Aires, Editorial ARcis CLAcso, 2013. 
Quiliconi, C., "The South American Regionalisms: A Shift or the Return of Economic Integration?”, en E. Vivares, Regionalism, Development and the Post-Commodities Boom in South America, Londres, Palgrave Macmillan, 2018.

Riggirozzi, P., "Re-territorializando consensos: hacia un regionalismo post-hegemónico en América Latina”, en A. Serbin, L. Martínez y H. Ramanzini Júnior, El regionalismo "post-liberal" en América Latina y el Caribe: nuevos actores, nuevos temas, nuevos desafios. Anuario de la integración regional de América Latina y el Gran Caribe 2012, Buenos Aires, CRIEs, 2012.

RiggirozzI, P., "Region, regionness and regionalism in Latin America: towards a new synthesis", New Political Economy 17 (4), 2012, pp. 421-443.

Riggirozzi, P. y D. E. Tussie, The rise of post-hegemonic regionalism: The case of Latin America, Países Bajos, Springer, 2012.

Russell, R. y J. G. Tokatlian, El lugar de Brasil en la política exterior argentina, Buenos Aires, Fondo de Cultura Económica, 2003.

Sáez Leal, J. y F. Rivas Molina, "Sudamérica entierra a la Unasur de Chávez, Kirchner y Lula”, El País, 22 de marzo de 2019, https://elpais.com/internacional/2019/03/22/argentina/1553281368_627367.html

Sanahuja, J. A., "Del 'regionalismo abierto' al 'regionalismo postliberal'. Crisis y cambio en la integración regional en América Latina” (pp. 11-54), Alfonso Martínez, L. Peña y M. Vázquez, Anuario de la Integración Regional de América Latina y el Gran Caribe, núm. 9L, Buenos Aires, crIEs, 2008.

Sanahuja, J. A., "Enfoques diferenciados y marcos comunes en el regionalismo latinoamericano: Alcance y perspectivas de Unasur y celac" (pp. 75-108), Pensamento Propio 39, 2014.

Sanahuja, J. A., "La ue y celac: Revitalización de una relación estratégica", Relaciones birregionales/Series de los Foros de Reflexión, 2015.

Schtremel, S., La "alianza estratégica" argentino-brasileña en el proceso de conformación de un subsistema internacional sudamericano. Lexis y praxis en la política externa brasileña hacia la Argentina, tesis doctoral, Universidad Nacional de Rosario, 2018. 
Serbin, A., "Déficit democrático y participación ciudadana en el marco del regionalismo post-liberal", Anuario de Integración Regional de América Latina y el Gran Caribe, A. Serbin, L. Martínez y H. O. Ramazini Jr., Buenos Aires, cries, 2012.

Serra, J., Discurso do ministro José Serra por ocasião da cerimônia de transmissão do cargo de ministro de estado das Relações Exteriores, 2016, http://www.itamaraty.gov.br/pt-BR/notas-aimprensa/14043-discurso-do-ministro-joseserra-por-ocasiaoda-cerimonia-de-transmissao-do-cargo-de-ministro-de-estadodasrelacoes-exteriores-brasilia-18-de-maio-de-2016

Sousa Ribeiro Pinchemel, E. de, "Paradigmas da atuação brasileira no Mercosul", Universitas: Relações Internacionais, vol. 9, núm. 1 (2011), pp. 297-330.

Souza, A., A agenda internacional do Brasil. A política externa brasileira de FHC a Lula, Río de Janeiro, CEBRI, 2009.

Sunkel, O., "Desarrollo e integración regional: ¿otra oportunidad para una promesa incumplida?", Revista de la CEPAL (número extraordinario), 1998, pp. 229-241.

VAdell, J., "La Argentina de Kirchner: el retorno del Estado en el siglo xxI y sus implicaciones en la política externa”, Análise de Conjuntura OPSA, 2008, pp. 1-21.

VAdell, J. A., "El Foro China-Celac y el nuevo regionalismo para un mundo multipolar: desafíos para la Cooperación 'Sur-Sur' ", Carta Internacional 13 (1), 2018, pp. 6-37.

VAn Klaveren, A., "El eterno retorno del regionalismo latinoamericano", Nueva Sociedad (275), 2018, pp. 62-72.

Vigevani, T. y G. Cepaluni, "A Política Externa de Lula da Silva: A Estratégia da Autonomia pela Diversificação", Contexto Internacional 29 (2), 2007, pp. 273-334.

Vigevani, T., G. Favaron, H. Ramanzini y R. A. Correia, "O Papel da Integração regional para o Brasil: universalismo, soberania e percepção da elites", Revista Brasileira de Política Internacional, 51 (1), 2008, pp. 5-27.

Vigevani, T., M. F. d. Oliveira y R. Cintra, "Política Externa no Periodo FHC: a busca de autonomia pela integração”, Tempo Social 15, 2003, pp. 31-61. 
Vivares, E., Regionalism, Development and the Post-Commodities Boom in South America, Londres, Palgrave Macmillan, 2018.

Vivares, E., P. Torres Lombardo y K. Cvetich, "Enfoques y cárceles conceptuales en el entendimiento de los Nuevos Regionalismos Latinoamericanos", en A. Bonilla y I. E. Álvarez, Desafíos Estratégicos del Regionalismo Contemporáneo: CELAC e Iberoamérica, San José, Costa Rica, Flacso, 2013.

Williamson, J., "What Washington means by policy reform", en J. Williamson, Latin American Adjustment: How Much Has Happened?, Washington, Institute for International Economics, 1990. 